\title{
Swine flu outbreak tests Canadian preparedness
}

First published at www.cmaj.ca on Apr. 28, 2009.

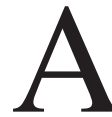

s Canada faces the first test of its pandemic influenza plan, the threat comes from much closer to home than experts expected.

"Everyone thought the next pandemic would come from Asia ... and there would be time to prepare. But holy cow it is Mexico, and cases are already here," says Dr. Ronald St. John, former director general of the Centre for Emergency Preparedness and Response, Public Health Agency of Canada.

Plans are always based on a set of assumptions, and Ontario's plan assumed a new strain of flu would originate in Asia "and we would have had a few weeks of readiness," agrees Dr. Vivek Goel, president of the Ontario Agency for Health Protection and Promotion.

Still, Canada's experience with severe acute respiratory syndrome (SARS) has paid off: Ontario and British Columbia were the first jurisdictions in the world to issue alerts, Goel says. "We had been looking at the Mexican media, and with the high volume of travel, particularly since we were just coming out of spring break, we realized it was something for people to be alert to."

Experts agree that Canada is far better prepared for a pandemic than it was before SARS. "After SARS there was a huge investment in pandemic preparedness," notes Theresa Tam, director general of the Centre for Emergency Preparedness and Response. The centre is the lead federal organization for coordinating responses for health related emergencies.

Ontario, for example, has conducted pandemic exercises, including a full scale test last fall, involving every ministry and region on the Ontario public service, to see how the health sector would be supported and critical government services maintained, says Phil Graham, interim director of the emergency management unit for the Ministry of Health and Long-Term Care.

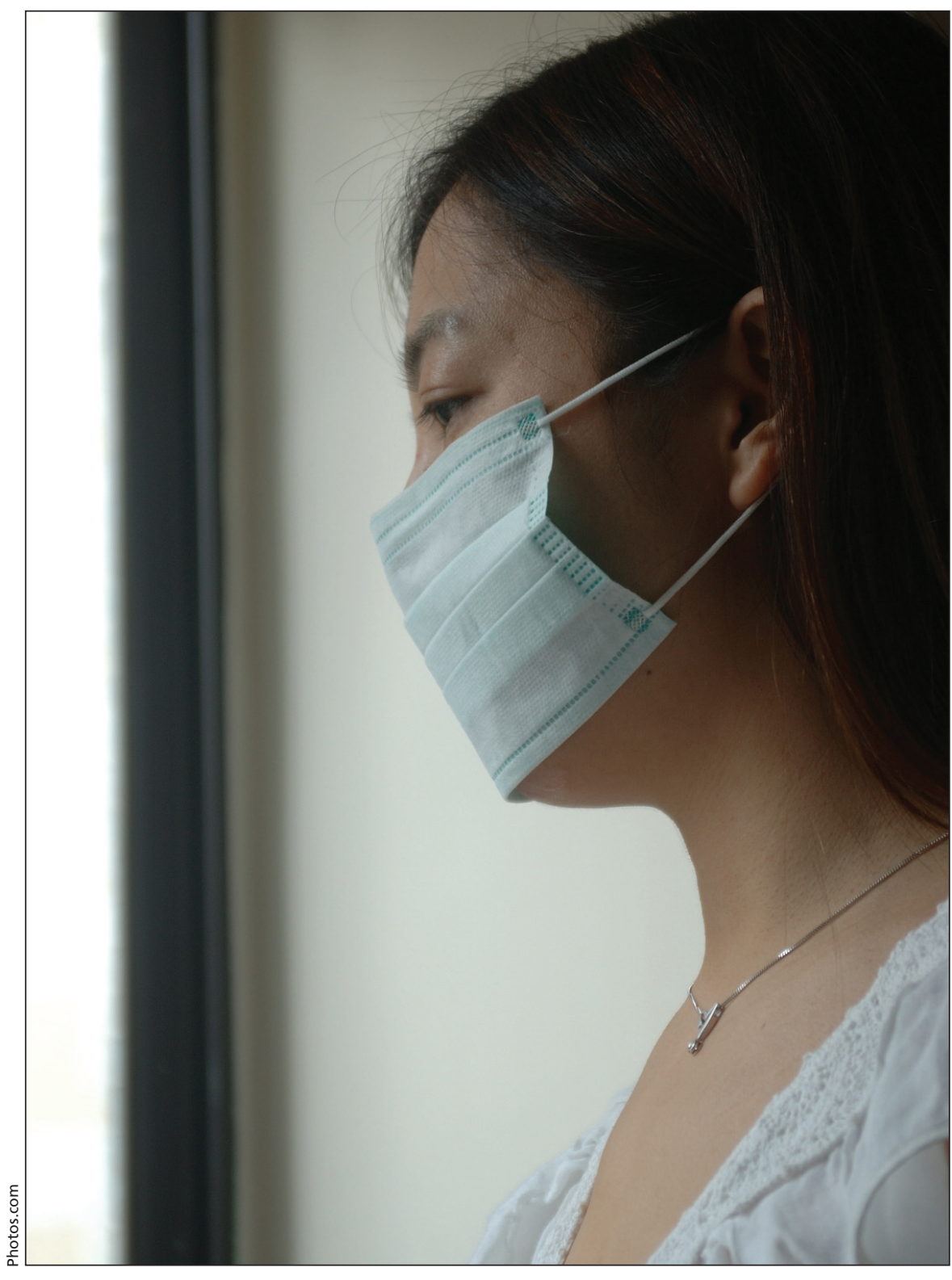

Ontario and British Columbia were the first jurisdictions in the world to issue swine flu alerts, a far cry from the sluggishness that was often evident during the 2003 SARS outbreak.

And in another lesson from SARS, the province has stockpiled supplies and equipment, such as N95 respirators, to protect health care workers in health emergencies, he notes. Antiviral drugs are also stockpiled in individual provinces and centrally at the National Emergency Stockpile System.
Graham stresses that although Ontario has done a lot of work since SARS, "nobody can expect it [preparedness] to be a light switch — like, yes, we are on, no we're off. It is so unpredictable it is difficult to say we are absolutely prepared for anything."

Meanwhile, it remains to be seen how 
the pandemic plans at various levels of government interlock. "No one has the answer to that," says Dr. Ross Upshur, associate professor in the University of Toronto faculty of medicine, director of the Joint Centre for Bioethics, and coauthor of Stand on Guard for Thee, Ethical Considerations in Preparedness Planning for Pandemic Influenza.

Upshur says that "broad public engagement" is needed to spread understanding about who has priority for antiviral treatment in a pandemic and high-level attention is needed to clarify triage rules and the obligations of health care workers during a pandemic.

Goel says his agency was criticized for possibly "calling wolf" when the alerts went out on Apr. 21. But he notes that it was only 2 days later that the United States Centers for Disease Control had identified the new $\mathrm{A}(\mathrm{H} 1 \mathrm{~N} 1)$ swine influenza strain from Mexico. The following day, the agency confirmed that an identical strain had been found in the US.

The real challenge now is how to connect with the front-line doctors in Canada, and keep them up to date but not overload them, Goel says.

In British Columbia, where 2 mild cases of the new strain of swine flu have been confirmed, the province has not seen "a big wave" of people showing up at hospitals or evidence of a sec- ond wave of transmission, Dr. David Patrick, director of epidemiology with the BC Centre for Disease Control, told a press conference on Apr. 27.

However, all models for disease outbreaks have "a lot of uncertainty" which is why initial patterns of transmission are being watched carefully, he said. The province has substantial stockpiles of antivirals, and the $\mathrm{A}(\mathrm{H} 1 \mathrm{~N} 1)$ strain has been shown to be responsive to antiviral treatment, although the $\mathrm{BC}$ patients did not require such treatment, he added.

Canada's 550-page Pandemic Influenza Plan spells out in detail the responsibilities of all levels of government in Canada.

Most emergency management and preparedness in Canada works from the bottom up: local municipalities have the first responsibility, and if their capacity is exceeded they call on their province, which in turn can call on the federal government for help if needed.

But since the situation has international dimensions, the federal government takes on the role of coordinating across jurisdictions.

"I am surprised at how well the public messaging is happening," says John Lindsay, chair of the applied disaster and emergency studies department at Brandon University in Brandon, Manitoba.

Lindsay explains that while the US declared a health emergency in order to access resources, "we don't need to do that. It is not that we are behind and need to catch up."

Canada's public health agency has been criticized because it has a formal disease surveillance agreement only with Ontario, but Tam notes that ministers of health recently agreed to a memorandum of understanding on information sharing and mutual aid in an emergency.

And groups like the council of health emergency management directors, with representatives from all provinces and territories and the federal government, meet regularly, she explains.

Meanwhile, the National Microbiology Laboratory in Winnipeg, Man., will soon be sending out rapid tests to the provincial public health laboratories so they can test more quickly for the $\mathrm{A}(\mathrm{H} 1 \mathrm{NI})$ virus, Goel says. Initial samples were sent to the national lab for specific genetic typing and to compare different strains.

Patrick says that Canadians can make themselves a "tough target" for the new strain of swine flu by staying home if they are experiencing a fever and cough and encouraging others with those symptoms to "take themselves out of circulation." - Ann Silversides, CMAJ

DOI:10.1503/cmaj.090805 